\title{
THE NATURAL HISTORY OF 271 PATIENTS WITH MITRAL STENOSIS UNDER MEDICAL TREATMENT
}

\author{
BY \\ KNUD H. OLESEN \\ From the Medical Department B, Rigshospitalet, (Chief: Professor Erik Warburg) University of Copenhagen, Denmark
}

Received November 6, 1961

This report is a follow-up of 271 patients with isolated mitral stenosis under medical treatment. The material comprises patients who came under medical care for cardiac symptoms during the years 1933-49. A first report of this series has already been published (Olesen, 1955). By 1959, 83 per cent of the patients had died, and the majority of survivors showed symptoms and signs of progression of the disease. On this background an analysis of the last follow-up data is presented as a contribution to the description of the natural history of mitral stenosis.

\section{MATERIAL AND MethodS}

The material comprises 271 patients with isolated mitral stenosis derived from the following sources: (1) 213 patients who were admitted to the Medical Department B, Rigshospitalet, University Hospital of Copenhagen, Denmark, under the care of Professor Erik Warburg during the years 1933-49, and (2) 58 who saw Professor Warburg in private consultation during the same period.

The clinical diagnosis of mitral stenosis was based upon the presence of a rough, rolling, or rasping diastolic or presystolic apical murmur. Patients with definite auscultatory signs of aortic valvular lesions were excluded. The material includes 261 patients with a sure clinical diagnosis and 10 patients with autopsy diagnosis.

The validity of the clinical diagnosis of mitral stenosis was checked in several ways: (1) 91 patients eventually came to autopsy, and mitral stenosis was verified in all instances, (2) at the clinical follow-up 78 patients were examined by the author in 1951-53, and 31 were re-examined in 1959, and the characteristic diastolic or presystolic murmurs were heard in all cases (in one patient an additional atrial septal defect was diagnosed), (3) 12 patients were subjected to mitral valvotomy during the period of observation and mitral stenosis was corroborated in all cases.

Complicating aortic valvular disease which had not been previously diagnosed was found at autopsy in 4 out of 91 cases and at clinical follow-up in 12 out of 78 patients. Tricuspid valvular stenosis occurred at autopsy in 5 out of 91 patients. Apparently the frequency of complicating aortic and tricuspid valvular lesions was low.

At the selection of the series all patients with a characteristic diastolic or presystolic apical murmur were grouped as mitral stenosis whether an apical systolic murmur had been present or not, since mitral regurgitation in the presence of signs of mitral stenosis traditionally had not been evaluated at the time of first observation. A total of 43 per cent of the series had an apical systolic murmur recorded, and this group may be assumed to comprise many patients with some degree of 
mitral regurgitation. Based on the correlation between auscultatory findings and palpation of the mitral ostium at operation in this hospital it is estimated that 14 per cent of the total material had had a significant degree of mitral regurgitation, whereas about 86 per cent had had dominant or pure mitral stenosis (Olesen, 1955).

The follow-up examinations were carried out in 1951-53 and in 1959. The periods of observation amounted to 3-20 years at the first follow-up, and to 10-26 years at the second follow-up, i.e. average periods of 11 and 18 years respectively.

Except for one patient who had emigrated, all patients were traced in 1951-53, and all survivors were traced again in 1959. The death certificates of the fatal cases and their hospital records during the period of observation were examined. At the first follow-up, 78 of 82 survivors were examined by the author, and at the second follow-up 31 of 45 survivors were re-examined. Sufficient information for evaluation was procured from other hospitals for one patient at the first follow-up and for nine at the second follow-up. Incomplete data were available for three and for five patients respectively.

For statistical evaluation, the survival data were treated according to the indirect or actuarial technique that includes the dead and the surviving patients. A comparison with the results of the direct survival calculation demonstrated a very high degree of accordance.

The patients received medical treatment according to the standard of the periods. After the first follow-up, 12 patients were subjected to mitral vavotomy: these have been included in the continued analysis. As 4 of these patients died postoperatively and a few others obviously materially did not benefit from the operation, it has been the author's conclusion that the operations could not alter the course of the whole series.

\section{SeRIES AT First ObSERVATION}

The essential characteristics of the 271 patients are given in Tables I and II.

TABLE I

Mitral Stenosis: Age Distribution at First ObServation

\begin{tabular}{|c|c|c|c|c|c|c|c|c|}
\hline Age groups (year & $14-19$ & $20-29$ & 30-39 & $40-49$ & $50-59$ & $60-69$ & $70-79$ & Total \\
\hline $\begin{array}{l}\text { Female patients } \\
\text { Male patients }\end{array}$ & $\begin{array}{l}5 \\
3\end{array}$ & $\begin{array}{l}23 \\
12\end{array}$ & $\begin{array}{l}59 \\
21\end{array}$ & $\begin{array}{l}60 \\
18\end{array}$ & $\begin{array}{l}36 \\
18\end{array}$ & $\begin{array}{r}10 \\
4\end{array}$ & $\begin{array}{l}1 \\
1\end{array}$ & $\begin{array}{r}194 \\
77\end{array}$ \\
\hline Total & 8 & 35 & 80 & 78 & 54 & 14 & 2 & 271 \\
\hline
\end{tabular}

Sex and Age. Women outnumbered men, the ratio being 2.5:1. The ages ranged from 14 to 73 years, the mean being 41.5 years for the two sexes. The median age was 42 years.

Stage of Disease. It is apparent from Table II that a great proportion of the series were in an advanced stage of the disease when the observation started. Atrial fibrillation was present in 57 per cent. Sixty-two per cent had cardiac enlargement, i.e. cardiothoracic index of 55 or more.

According to the American Heart Association's classification, 21 per cent belonged to Class II, 59 per cent to Class III, and 20 per cent to Class IV.

As a result of survival studies the author in 1955, suggested a classification of symptomatic mitral stenosis as follows.

Group A. Patients with normal sinus rhythm belonging to Class II.

Group B. Patients with normal sinus rhythm belonging to Class III.

Group C. Patients with atrial fibrillation belonging to Class II or III.

Group D. Patients belonging to Class IV. 
TABLE II

Stage of Mitral Stenosis at First Observation

\begin{tabular}{|c|c|c|c|c|c|c|c|c|}
\hline & & & \multicolumn{2}{|c|}{ Women } & \multicolumn{2}{|c|}{ Men } & \multicolumn{2}{|c|}{ Total } \\
\hline & & & Number & Per cent & Number & Per cent & Number & Per cent \\
\hline & & & 194 & & 77 & & 271 & \\
\hline $\begin{array}{l}\text { Heart Rhythm } \\
\text { Normal sinus }\end{array}$ & & $\begin{array}{l}. . \\
.\end{array}$ & $\begin{array}{r}88 \\
106\end{array}$ & $\begin{array}{l}45 \\
55\end{array}$ & $\begin{array}{l}28 \\
49\end{array}$ & $\begin{array}{l}36 \\
64\end{array}$ & $\begin{array}{l}116 \\
155\end{array}$ & $\begin{array}{l}43 \\
57\end{array}$ \\
\hline $\begin{array}{c}\text { Heart Size } \\
\text { Normal ... } \\
\text { Enlarged }\end{array}$ & 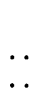 & $\ddot{.}$ & $\begin{array}{r}65 \\
117\end{array}$ & $\begin{array}{l}36 \\
64\end{array}$ & $\begin{array}{l}34 \\
35\end{array}$ & $\begin{array}{l}49 \\
51\end{array}$ & $\begin{array}{r}99 \\
152\end{array}$ & $\begin{array}{l}40 \\
60\end{array}$ \\
\hline $\begin{array}{c}\text { Functional Cap } \\
\text { Class II .. } \\
\text { Class III } \\
\text { Class IV }\end{array}$ & $\begin{array}{l}\text { ity } \\
\ldots \\
. . \\
. .\end{array}$ & $\begin{array}{l}. \\
\therefore \\
.\end{array}$ & $\begin{array}{r}40 \\
117 \\
37\end{array}$ & $\begin{array}{l}21 \\
60 \\
19\end{array}$ & $\begin{array}{l}18 \\
43 \\
16\end{array}$ & $\begin{array}{l}23 \\
56 \\
21\end{array}$ & $\begin{array}{r}58 \\
160 \\
53\end{array}$ & $\begin{array}{l}21 \\
59 \\
20\end{array}$ \\
\hline $\begin{array}{l}\text { Author's Classi } \\
\text { Group A } \\
\text { Group B } \\
\text { Group C } \\
\text { Group D }\end{array}$ & $\begin{array}{l}\text { atio } \\
. \\
\therefore \\
. \\
.\end{array}$ & $\begin{array}{l}. \\
. \\
.\end{array}$ & $\begin{array}{l}30 \\
51 \\
76 \\
37\end{array}$ & $\begin{array}{l}15 \\
26 \\
40 \\
19\end{array}$ & $\begin{array}{r}8 \\
16 \\
37 \\
16\end{array}$ & $\begin{array}{l}10 \\
21 \\
48 \\
21\end{array}$ & $\begin{array}{r}38 \\
67 \\
113 \\
53\end{array}$ & $\begin{array}{l}14 \\
24 \\
42 \\
20\end{array}$ \\
\hline $\begin{array}{cc}\text { Right Axis } & \text { Dev } \\
\text { Present } & \ldots \\
\text { Absent } & \ldots\end{array}$ & $\begin{array}{l}\text { tion } \\
. \\
. .\end{array}$ & 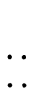 & $\begin{array}{r}55 \\
137\end{array}$ & $\begin{array}{l}29 \\
71\end{array}$ & $\begin{array}{l}23 \\
54\end{array}$ & $\begin{array}{l}30 \\
70\end{array}$ & $\begin{array}{r}78 \\
191\end{array}$ & $\begin{array}{l}29 \\
71\end{array}$ \\
\hline $\begin{array}{l}\text { Increased Hilar } \\
\text { Markings } \\
\text { Present } \ldots \\
\text { Absent } \ldots\end{array}$ & 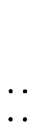 & 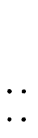 & $\begin{array}{r}50 \\
105\end{array}$ & $\begin{array}{l}33 \\
67\end{array}$ & $\begin{array}{l}27 \\
39\end{array}$ & $\begin{array}{l}42 \\
58\end{array}$ & $\begin{array}{r}77 \\
144\end{array}$ & $\begin{array}{l}35 \\
65\end{array}$ \\
\hline $\begin{array}{c}\text { Apical Systolic } \\
\text { Present } \quad . . \\
\text { Absent } \quad .\end{array}$ & $\begin{array}{l}\text { Iurn } \\
. . \\
. .\end{array}$ & .. & $\begin{array}{r}81 \\
113\end{array}$ & $\begin{array}{l}42 \\
58\end{array}$ & $\begin{array}{l}35 \\
42\end{array}$ & $\begin{array}{l}45 \\
55\end{array}$ & $\begin{array}{l}116 \\
155\end{array}$ & $\begin{array}{l}43 \\
57\end{array}$ \\
\hline
\end{tabular}

The distribution of the series according to this classification is as follows. Group A: 38 patients $(14 \%)$. Group B: 67 patients $(24 \%)$. Group C: 113 patients $(42 \%)$. Group D: 53 patients $(20 \%)$.

Right axis deviation was present in 29 per cent of the series. Increased hilar markings were noted in 35 per cent of the patients with an adequate radiological examination.

\section{RESULTS OF FOLLOW-UP}

The main results of the first and second follow-up are given in Table III.

At the first follow-up in 1951-53 a total of 189 out of 271 patients had died (or $70 \%$ ). At the second follow-up in 1959 a total of 226 out of 271 had died (or $83 \%$ ).

Age at Death and Causes of Death. The ages at death ranged from 14 to 78 years. The mean age at death was 48.0 years, slightly lower in men ( 46.5 years) than in women (48.6 years). The median age was 49 years.

A classification according to causes of death revealed that 62 per cent died from congestive heart failure or pulmonary œdema, 22 per cent from thrombo-embolic complications, and 8 per cent from infections. Thus, a total of 92 per cent died from causes usually attributed to mitral stenosis.

Age of Survivors. At the first follow-up, 82 patients were alive at a mean age of $49 \cdot 1$ years, while 189 had died at a mean age of $47 \cdot 0$ years. At the second follow-up the 45 survivors had 
TABLE III

Mitral Stenosis: Results OF Follow-UP IN 1951-53 AND IN 1959

\begin{tabular}{|c|c|c|c|c|c|c|c|c|}
\hline & & & & & \multicolumn{2}{|c|}{ Follow-up 1951-53 } & \multicolumn{2}{|c|}{ Follow-up 1959} \\
\hline & & & & & Number & Percentage & Number & Percentage \\
\hline $\begin{array}{l}\text { Dead } \\
\text { Deterior } \\
\text { Unchan } \\
\text { Incompl }\end{array}$ & $\begin{array}{l}\text { rated } \\
\text { ged } \\
\text { lete data }\end{array}$ & $\begin{array}{l}\ddot{.} \\
\ddot{a}\end{array}$ & $\begin{array}{l}\ldots \\
\cdots \\
\cdots \\
\cdots\end{array}$ & $\begin{array}{l}\ldots \\
\cdots \\
\cdots\end{array}$ & 189 & $\begin{array}{r}18 \\
11 \\
1\end{array}$ & $\begin{array}{r}32 \\
8 \\
5 \\
-\end{array}$ & $\begin{array}{r}12 \\
3 \\
2 \\
-\end{array}$ \\
\hline Survivors & .. & .. & . & .. & 82 & 30 & 45 & 17 \\
\hline Total & .. & $\cdots$ & .. & .. & 271 & & 271 & \\
\hline
\end{tabular}

a mean age of 54.6 years whereas the mean age for the total group of those who had died was 48.0 years. Apparently the group of survivors at both follow-up's included a number of older patients with mitral stenosis, a finding that is well known from this type of study and one that makes it necessary to include the survivors in any analysis that attempts to describe the course of the disease for the whole group.

Deterioration in Survivors. The development of one or more of the following features during the period of observation was taken as evidence of deterioration: the manifestation of chronic atrial fibrillation, of right heart failure, of thrombo-embolic complications, of an increase in heart size or an impairment of functional capacity. By this definition 32 out of 45 survivors (or $12 \%$ of the total series) showed signs of deterioration during the period of observation, whereas only 8 patients (or $3 \%$ of the total series) were in an unchanged condition. Two per cent had incomplete data for this classification, but even if they are assumed to belong to the best group the trend towards deterioration among the survivors is evident. It is apparent from Table III that this trend continued between the first and the second follow-up. In the total series the percentage of survivors decreased from 30 to 17, and this decrement was paralleled by a decrease in the percentage of unchanged condition from 11 to 3 , or with inclusion of those with incomplete data from possibly 12 to 5 .

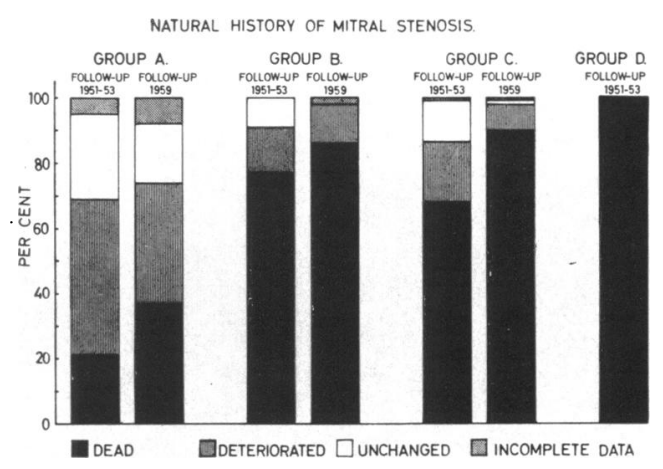

FIG. 1.-Rates of death and of progression of mitral stenosis at the first and second follow-up according to author's classification of the material (see text).

This pattern of change was present in all groups as shown in Fig. 1 which summarizes the results of the two follow-up's according to the author's classification of the original material. 


\section{Assessment of Prognosis}

With the development of mitral valvotomy as an operation with an acceptable mortality and with the prospect of improvement of the majority of patients, the problem of an accurate prognosis under a conservative regimen has received increased attention. On this background the material presented will be subjected to a more detailed analysis with regard to the survival rates in relation to various criteria related to the stage or degree of mitral stenosis.

Statistical Considerations. The analysis will be based upon the data from the last follow-up. The presentation is given in terms of survival rates calculated by the actuarial or indirect techniques (Olesen, 1955). Mostly the 10- and 20-year survival rates are used. In a few instances the total survival curves will be presented.

The validity of the procedure is borne out by the following two checks. (1) The survival rates calculated by the actuarial technique are in good accordance with those obtained by the direct survival calculation. In the order mentioned the 10-year survival percentages are 34 and 32 , and the 20-year survival percentages 14 and 15 respectively.

(2) Since it might be possible that alterations in therapy in the course of time might influence the long-term prognosis, the 5-and 10-year survival rates for the first and the second half of the series were examined. In the material collected during the years 1933-40 the 5- and 10-year survival percentages are 57 and 34, and in the series collected from 1941 to 1949 the corresponding values are 56 per cent and 36 per cent. Therefore, it seems justifiable to use the series as a whole in the subsequent analysis.

Survival of Total Series. For the total series of 271 patients the median survival time amounted to 6-7 years. The survival rate after 10 years was 34 per cent and after 20 years, 14 per cent as shown in Fig. 2.

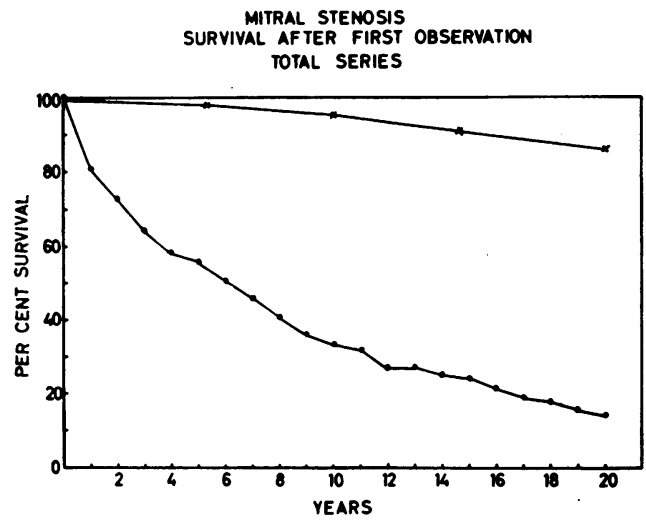

Fig. 2.-Survival of total series of mitral stenosis after first observation (lower curve) compared with the survival of the population of Denmark (upper curve).

Influence of Mitral Regurgitation. As mentioned earlier, there is reason to believe that a group of patients with concomitant mitral regurgitation has been included in the material, but no attempt was made at the time of the first observation to identify the patients with significant regurgitation. Since a mitral systolic murmur is an almost indispensable component in the present-day clinical diagnosis of preponderant mitral regurgitation it is reasonable to assume that the group of patients in whom an apical systolic murmur was described will contain the majority of cases with a significant degree of mitral regurgitation. On the other hand the group with pure diastolic murmurs will be almost entirely free of mitral regurgitation. 
In patients with an apical systolic murmur the survival rate after 10 years is 29 per cent and after 20 years 11 per cent. In the absence of an apical systolic murmur the corresponding figures are 36 per cent and 15 per cent respectively. The conclusion is that the prognosis for pure mitral stenosis is only a little better than that for combined mitral stenosis and regurgitation.

Influence of Sex and Age. The 10- and 20-year perspectives were more favourable in women than in men, in spite of the fact that the two sexes had the same average age at the start of the observation (Table IV). This discrepancy is also reflected in the fact that the mean age at death was lower in men than in women.

TABLE IV

Mitral Stenosis: Ten and Twenty Year Survival Rates in Relation to Age and SeX

\begin{tabular}{|c|c|c|c|c|}
\hline & & & $\begin{array}{l}\text { After ten years } \\
\text { (percentage) }\end{array}$ & $\begin{array}{l}\text { After twenty years } \\
\text { (percentage) }\end{array}$ \\
\hline $\begin{array}{l}\text { Sex } \\
\text { Women } \\
\text { Men }\end{array}$ & .. & $\ddot{n}$ & $\begin{array}{l}38 \\
23\end{array}$ & $\begin{array}{r}17 \\
5\end{array}$ \\
\hline $\begin{array}{l}\text { Age } \\
\text { Below } 35 \text { years } \\
35-49 \text { years ... } \\
50 \text { years or more }\end{array}$ & $\begin{array}{l}. \\
\ldots \\
\ldots\end{array}$ & $\begin{array}{l}\ldots \\
\ldots \\
\ldots\end{array}$ & $\begin{array}{l}33 \\
40 \\
25\end{array}$ & $\begin{array}{r}25 \\
13 \\
0\end{array}$ \\
\hline
\end{tabular}

Increasing age usually denotes that the mitral stenosis is in a more advanced stage. As shown in Table IV, the patients over the age of 50 years demonstrated lower survival rates than the younger age groups. That the stage of the disease may be more important than the age itself is reflected in the higher survival rate after ten years for the middle-aged group as contrasted with the youngest age group.

Heart Rhythm, Heart Size, and Functional Capacity in Relation to Survival. Established atrial fibrillation is usually accepted as a manifestation of advanced mitral stenosis. It is in accordance with this concept that patients with atrial fibrillation have a 10-year suvival rate of 25 per cent and a 20-year survival rate of 0 per cent whereas patients with normal sinus rhythm have 46 per cent survivors after 10 years and 29 per cent survivors after 20 years.

The same pattern is found when patients with enlargement of the heart are contrasted with patients with a normal heart size (i.e., a cardiothoracic index less than $55 \%$ ). In the former group 25 per cent are alive after 10 years and $/ 7$ per cent alive after 20 years. In the latter group the corresponding figures are 51 and 29 per cent respectively.

An analysis of the survival rates related to functional capacity demonstrates the same trends. Patients in Class II have 10- and 20-year survival percentages of 69 and 49 respectively. Patients in Class III have 33 and 0 respectively. In Class IV all patients are dead within 10 years.

Survival in Relation to Author's Classification. The survival data according to the classification by the author in 1955 are given in Fig. 3.

Patients belonging to group A have a 10-year survival rate of 82 per cent and a 20 -year survival rate of 70 per cent. Patients in group B and group C have 10-year survival rates of 35 and 34 per cent and 20-year survival rates of 13 and 0 per cent respectively. In group D all patients died within the first 10 years.

Influence of Right Axis Deviation and of Increased Hilar Markings upon Survival. Right axis deviation was present in 29 per cent of the total series, and increased hilar markings were noticed in 35 per cent of those with adequate radiological examination. Since these signs may be assumed to separate groups with prevalence of high pressures in the pulmonary circulation as contrasted with groups with absence of these signs, the prognostic implications of right axis deviation and of increase in hilar markings are of interest. 


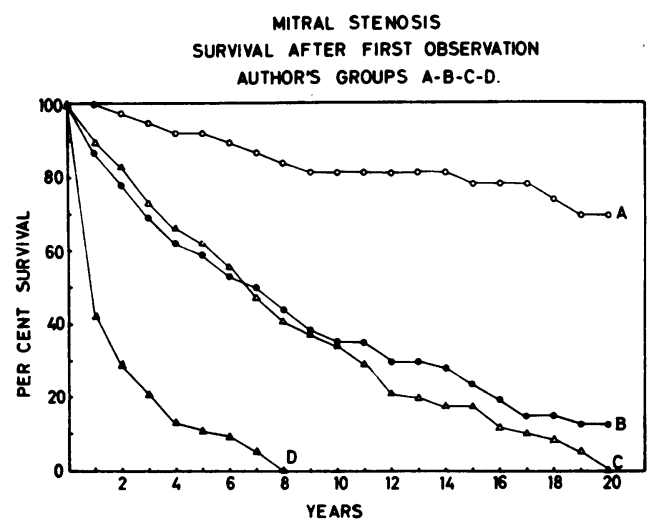

Fig. 3.-Survival after first observation according to author's classification in groups A, B, C, and $\mathbf{D}$.

TABLE V

Mitral Stenosis: Right Axis Deviation and InCreased Hilar Markings in Relation to Survival. Total Series

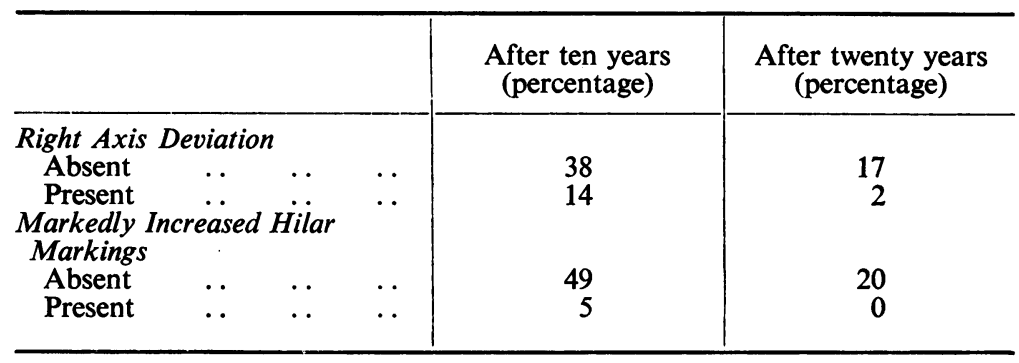

TABLE VI

Mitral Stenosis: Right Axis Deviation and Increased Hilar Markings in Relation to Survival in Groups B aNd C

\begin{tabular}{|c|c|c|c|c|c|}
\hline & & & & $\begin{array}{l}\text { After ten years } \\
\text { (percentage) }\end{array}$ & $\begin{array}{l}\text { After twenty years } \\
\text { (percentage) }\end{array}$ \\
\hline \multicolumn{6}{|c|}{$\begin{array}{c}\text { Right Axis Deviation } \\
\text { Goup } B\end{array}$} \\
\hline \multirow{2}{*}{$\begin{array}{l}\text { Absent } \\
\text { Present }\end{array}$} & . & .. & . & 40 & 15 \\
\hline & . & . & . & 14 & 5 \\
\hline \multicolumn{6}{|l|}{ Group C } \\
\hline Absent & . & $\ldots$ & . & 37 & 0 \\
\hline Present & - & . & . & 24 & 0 \\
\hline \multicolumn{6}{|c|}{$\begin{array}{l}\text { Increased Hilar Markings } \\
\text { Group B }\end{array}$} \\
\hline Absent & .. & .. & .. & 46 & 22 \\
\hline Present & . & . & . & 5 & 0 \\
\hline \multicolumn{6}{|l|}{ Group $C$} \\
\hline Absent & $\cdots$ & $\ldots$ & $\ldots$ & 46 & 0 \\
\hline Present & . & .. & .. & 12 & 0 \\
\hline
\end{tabular}


It appears from Table $\mathrm{V}$ that the presence of right axis deviation or increased hilar markings indicates much lower survival rates than found in the absence of these signs.

These tendencies are also present in groups B and C, as shown in Table VI.

\section{Discussion}

The second follow-up examination of these patients with mitral stenosis expands and confirms the results of the first (Olesen, 1955). The continued progression of symptomatic mitral stenosis is clearly demonstrated. The mortality increased from 70 per cent after an average period of 11 years to 83 per cent after 18 years. During the same period the group who presented an unchanged condition decreases from 12 per cent to 3 per cent, or when patients with incomplete data are included from possibly 13 per cent to 5 per cent. These trends are similar whether an apical systolic murmur was present or not.

These data are based upon a series of patients who presented themselves with cardiac symptoms, and many patients were in a rather advanced stage of the disease when they were included in the material. Therefore, the mortality in the present series is higher than in other follow-up studies.

The author's series is most comparable with the series of Wilson and Greenwood (1954). These authors followed 171 patients with mitral stenosis for an average period of 14 years. The mortality amounted to 70 per cent, and the average age at death was 45 years. Grant (1933) reported a 10year follow-up of 238 male soldiers with mitral stenosis, but his series was on an average 10 years younger and contained a larger group with slight symptoms in comparison with the author's material (Olesen, 1955). Consequently the 10-year survival was higher in Grant's total series (58\%) than in the author's material $(34 \%)$. When the stages of the disease were considered however, a fairly good agreement between the two series was present. Recently Rowe et al. (1960) reported their 10and 20-year follow-up of mitral stenosis: out of 250 patients, 61 per cent survived after 10 years, and out of 115 patients 21 per cent survived after 20 years. This series also contained more young patients without or with only slight symptoms. However, when the grouping according to severity of the disease was considered the tendencies to increasing mortality with increasing disability were exactly the same in the two series. Also the continued progression at later follow-up in the two series was in full accordance.

The experiences of the author and of other investigators are in agreement that symptomatic mitral stenosis in the majority of cases is a progressive disease with a grave prognosis. The survival data indicate the desirability of an improvement in therapy. Mitral valvotomy has now been established as a reasonably safe and effective procedure (Ellis et al., 1959; Olesen and Baden, 1961) and should be considered in the treatment of mitral stenosis. Within these groups, patients with established pulmonary hypertension or with progressive symptoms should be evaluated for operation.

The present study did not contain patients with asymptomatic mitral stenosis. However, in a group with slight to moderate symptoms and normal sinus rhythm at the first observation the survival rates were so high that from this criterion alone operation cannot be indicated for this group as a whole. This attitude would also apply to asymptomatic mitral stenosis.

In more advanced mitral stenosis the course was progressive and the mortality very high. Patients with progressive and advanced mitral stenosis should be evaluated for mitral valvotomy.

Patients with right axis deviation and/or increased hilar markings had a much higher mortality than those without such signs. These patients presumably had pulmonary hypertension, a group in particular need of relief of mitral stenosis. Within these groups, patients with established pulmonary hypertension or with progressive symptoms should be evaluated for operation.

Follow-up studies of operated mitral stenosis for up to 9 years after valvotomy have demonstrated that operated patients live longer than medically treated patients (Ellis et al., 1959; Rowe et al., 1960; Boyle, 1961; Olesen and Baden, 1961). It appears from the data presented that even longer periods of follow-up may be necessary for a final evaluation of the benefit that patients with mitral stenosis may derive from operation. 
This series is presented as a background material for the evaluation of the prospects of mitral stenosis under medical treatment.

\section{SUMMARY}

Two hundred and seventy-one patients with symptomatic mitral stenosis who were first seen during the years 1933-49 were followed up in 1951-53 and again in 1959.

At the first observation the series had an average age of 41.5 years. A great proportion were in an advanced stage of the disease. Fifty-seven per cent had chronic atrial fibrillation and 62 per cent enlargement of the heart, i.e. a cardiothoracic index of 55 or more. Right axis deviation was present in 29 per cent. Increased hilar markings were noted in 35 per cent of those with adequate radiological examination.

At the follow-up -after an average period of eleven years-a total of 70 per cent of the series were dead, 18 per cent had deteriorated, and 11 per cent were unchanged, 1 per cent having incomplete data. At the second follow-up-after 18 years-a total of 83 per cent were dead, 12 per cent had deteriorated, and 3 per cent were unchanged, 2 per cent having incomplete data.

Sixty-two per cent died from cardiac failure, 22 per cent from thrombo-embolic complications, 8 per cent from infections, and 8 per cent from unrelated causes.

For the total series the survival rates were 34 per cent after 10 years and 14 per cent after 20 years. These results were similar whether an apical systolic murmur had been present or absent.

Women had a slightly higher survival than men, and younger patients did better than those over the age of 50 years.

Patients with atrial fibrillation and with enlarged hearts had a lower survival than found in the absence of these signs. Decreasing functional capacity was associated with decreasing survival rate.

Patients with right axis deviation or with increased hilar markings had a lower survival than patients without these signs.

The continued tendency to progression of mitral stenosis giving rise to symptoms is stressed and the advisability of operation is discussed.

\section{REFERENCES}

Boyle, D. McC. (1961). Brit. Heart J., 23, 377.

Ellis, L. B., Harken, D. E., and Black, H. (1959). Circulation, 19, 803.

Grant, R. T. (1933). Heart, 16, 275.

Olesen, K. H. (1955). Mitral Stenosis. A Follow-up of 351 Patients. Munksgaard (editor), Copenhagen.

- and Baden, H. (1961). Acta chir. scand. Suppl. 283, 116.

Rowe, J. C., Bland, E. F., Sprague, H. B., and White, P. D. (1960). Ann. intern. Med., 52, 741.

Wilson, M. G., and Greenwood, W. F. (1954). Canad. med. Ass. J., 71, 323. 